\title{
Viral meningitis: an overview
}

\author{
Amira Kohil $^{1} \cdot$ Sara Jemmieh ${ }^{1} \cdot$ Maria K. Smatti $^{2} \cdot$ Hadi M. Yassine ${ }^{2} \mathbb{D}$
}

Received: 24 June 2020 / Accepted: 4 October 2020 / Published online: 3 January 2021

(c) Springer-Verlag GmbH Austria, part of Springer Nature 2021

\begin{abstract}
Meningitis is a serious condition that affects the central nervous system. It is an inflammation of the meninges, which is the membrane that surrounds both the brain and the spinal cord. Meningitis can be caused by bacterial, viral, or fungal infections. Many viruses, such as enteroviruses, herpesviruses, and influenza viruses, can cause this neurological disorder. However, enteroviruses have been found to be the underlying cause of most viral meningitis cases worldwide. With few exceptions, the clinical manifestations and symptoms associated with viral meningitis are similar for the different causative agents, which makes it difficult to diagnose the disease at early stages. The pathogenesis of viral meningitis is not clearly defined, and more studies are needed to improve the health care of patients in terms of early diagnosis and management. This review article discusses the most common causative agents, epidemiology, clinical features, diagnosis, and pathogenesis of viral meningitis.
\end{abstract}

\section{Introduction}

Meningitis is an inflammation that affects the three protective membrane layers that cover the brain and spinal cord, called the meninges [1]. The outer layer of the meninges is called the dura mater, followed by the arachnoid mater and the pia mater. The two inner layers (arachnoid and pia mater) are also called the leptomeninges and are separated by the subarachnoid space, which contains cerebrospinal fluid (CSF) [2]. Aseptic meningitis, also known as slow viral disease, became an area of interest at the beginning of the 1950s, when it was considered a potential model for chronic nervous system diseases [3]. Bacteria are the most common causative agents of meningitis. However, viruses, fungi, and non-infectious agents such as drugs can also induce meningitis [2]. Pathogens can reach the CSF through hematogenous spread by two main mechanisms: 1) by infecting immune cells, which in turn carry the pathogen to the nervous system, and 2) by crossing blood capillaries and entering the CSF as free pathogens [4]. The term aseptic meningitis is used to describe meninges inflammation that is caused by

Handling Editor: Akbar Dastjerdi.

Hadi M. Yassine

hyassine@qu.edu.qa

1 Department of Biomedical Sciences, College of Health Sciences, QU Health, Qatar University, Doha, Qatar

2 Biomedical Research Center, Qatar University, Doha, Qatar pathogens other than pus-producing bacteria [5]. Viral meningitis is the most common type of aseptic meningitis and usually affects young children [1]. Enteroviruses (EVs) are the most common causative agents of viral meningitis, with an estimated 75,000 new cases annually in the United States [6]. Here, we provide an overview of viral meningitis and its most common causative agents and their pathogenesis. We also discuss epidemiological aspects, diagnosis, and clinical manifestations of the disease.

\section{Epidemiology}

Viral meningitis occurs throughout the year, but it is most commonly seen in summer and autumn [7]. A study conducted in England between 2011 and 2014 showed that the incidence of viral meningitis was 2.73 per 100,000 , with the largest number of cases caused by non-polio enteroviruses [8]. Another study in the United Kingdom (UK) showed that the incidence of viral meningitis caused by EV and human parechovirus $(\mathrm{HPeV})$ is double that of bacterial meningitis [9]. In addition, a study done in Denmark showed similar findings, with non-polio enteroviruses being the most common causative agent. They also showed that the incidence of aseptic meningitis decreases with increasing age (58.7 per 100,000 after birth, 38.7 per 100,000 in 6-month-old infants, and 15.6 per 100,000 in 5-year-old children) [10] (Table 1). Also, a study conducted in China found that viral meningitis caused by EV-71 accounted for approximately 
$55.2 \%$ of neurological disorders [11]. In South Africa, children less than 10 years of age constituted $87.3 \%$ of those affected by an aseptic meningitis outbreak in which the responsible pathogen was coxsackievirus A9 [12]. In Austria (2001-2004), 56\% of the patients included in a study had viral meningitis, where E-30 (36.4\%), coxsackievirus-B (19.6\%), and EV-71 (13.1\%) were the viruses that were most frequently found [13]. The most recently detected viral agent causing meningitis was reported in a case study of a 24-yearold male from Japan who had aseptic meningitis caused by SARS-CoV-2, which was demonstrated by performing an RT-PCR test on a CSF sample from the patient. This case report indicates the possible neuroinvasive potential of
SARS-CoV-2 and its potential to cause CNS complications such as meningitis [14] (Tables 1 and 2).

A number of studies have been conducted to evaluate the epidemiology of viral meningitis in the Middle East and North Africa (MENA) region (Table 3). Based on earlier studies in the Gulf region between 2000 and 2005, 37\% of meningitis cases in the United Arab Emirates (UAE) were caused by viral infections, with a mortality rate of $3 \%$. The same study also showed that children and young adults are the most affected age group [15]. In another study from Kuwait, it was shown that 387 patients (mainly pediatric patients) had aseptic meningitis, with the most common viral agents being echovirus 9 (E-9), E-11 and E-30, accounting

Table 1 Epidemiology of viral meningitis in children worldwide

\begin{tabular}{|c|c|c|c|c|c|c|}
\hline Country & Years & Number of cases $\mathrm{n}(\%)$ & Incidence & $\begin{array}{l}\text { Common causative } \\
\text { agent }\end{array}$ & $\begin{array}{l}\text { Most common clinical } \\
\text { manifestation }\end{array}$ & Reference \\
\hline Denmark & $1977-2001$ & 1642 cases & $\begin{array}{l}38.7 \text { per } 100,000 \\
\quad(6 \text {-month-old infants) }\end{array}$ & $\begin{array}{l}\text { Mumps and non-polio } \\
\text { enteroviruses }\end{array}$ & - & {$[10]$} \\
\hline Fiji (South Pacific) & $2004-2007$ & $12(17.1 \%)$ & - & $\mathrm{EV}$ & Fever & [110] \\
\hline USA & $2005-2011$ & 7618 cases & - & $\mathrm{EV}$ & Fever and headache & [111] \\
\hline China & 2013 & $74(55.2 \%)$ & - & EV-71 & $\begin{array}{l}\text { Fever and myoclonic } \\
\text { seizures }\end{array}$ & {$[11]$} \\
\hline England & 2014-2015 & 703 cases & $\begin{array}{l}\mathrm{EV}=0.79 \text { per } 1000 \\
\mathrm{HPeV}=0.04 \text { per } 1000 \\
\text { for }\end{array}$ & $\mathrm{EV}$ and $\mathrm{HPeV}$ & Fever and irritability & [9] \\
\hline
\end{tabular}

Table 2 Epidemiology of viral meningitis in adults worldwide

\begin{tabular}{llllll}
\hline Country & Years & Number of cases n (\%) & Common causative agent & Most common clinical manifestation & Reference \\
\hline Greece & $2003-2006$ & $36(44.4 \%)$ & EV, VZV, and HSV-2 & - & Headache and fever \\
South Korea & $2008-2013$ & $96(54.2 \%)$ & EV and VZV & Fever and headache & [112] \\
Italy & $2002-2006$ & $162(80 \%)$ & - & Headache and photophobia & [114] \\
England & $2011-2014$ & $638(57 \%)$ & Non-polio enteroviruses & Headache and photophobia \\
Finland & $1999-2003$ & $95(66 \%)$ & EV & {$[115]$} \\
\hline
\end{tabular}

Table 3 Epidemiology of viral meningitis in the MENA region

\begin{tabular}{llllll}
\hline Country & Years & $\begin{array}{l}\text { Number of patients with } \\
\text { meningitis n (\%) }\end{array}$ & Common causative agent & Most common clinical manifestation & Reference \\
\hline Jordan & 1999 & 32 cases & E-9 and Coxsackievirus B4 & Fever and vomiting & Fever \\
& 2001 & 474 cases & - & Fever & [116] \\
& 2014 & 463 cases & - & - & {$[19]$} \\
Egypt & 2007 & $17(6.8 \%)$ & EV and HSV & Fever and signs of meningeal irritations \\
& $2010-2012$ & 100 cases & EV & Fever \\
Kuwait & $2003-2006$ & 387 cases & E-9, E-11 and E-30 & Fever and neck stiffness \\
UAE & $2000-2005$ & $34(37 \%)$ & - & Fever and headache \\
Qatar & $2011-2015$ & $411(74.7 \%)$ & EV & Fever and vomiting \\
Palestine & $2013-2014$ & $80(62 \%)$ & EV & Fever and headache \\
& $2012-2015$ & 356 cases & EV-B & & {$[16]$} \\
\hline
\end{tabular}


for $24 \%$ of the cases [16]. In Qatar, it has been estimated that the incidence of viral meningitis from 2011 to 2015 was 6.4 per 100,000 , with most cases being children infected with EV [17]. Additionally, a three-year study (2013-2015) in Egypt indicated that 573 out of 1337 meningitis cases $(42.86 \%)$ were due to viral infections [18]. Moreover, higher percentages of viral meningitis were reported in Jordan, reaching $83 \%$ of all meningitis cases between 2001 and 2004, and $81 \%$ in 2014 [19]. In a two-year study in Gaza (2013-2014), 72\% of meningitis cases were classified as viral meningitis, caused mainly by an EV infection (35\%) [20]. A different study in Palestine on EV-positive aseptic meningitis cases found that the most affected age group was children less than one year old, accounting for $64 \%$. Also, $58 \%$ of the cases were detected in spring and summer, while $42 \%$ were detected in fall and winter [21]. According to the Palestinian Ministry of Health, the incidence of aseptic meningitis is 6.8 per 100,000 in the West Bank and 247 per 100,000 in the Gaza Strip [21]. Furthermore, a study in Lebanon showed that $82.7 \%$ of study subjects were diagnosed with viral meningitis, while only $17.3 \%$ were diagnosed with bacterial meningitis [22]. In Egypt, out of 250 confirmed cases of meningitis, 17 were caused by viral agents, and the most commonly encountered viruses were $\mathrm{EV}$, herpes simplex virus (HSV), and varicella zoster virus (VZV) [23]. Another study in Egypt done on pediatric patients with aseptic meningitis found that $56 \%$ of cases were due to EV [24].

\section{Clinical manifestations and diagnosis}

Although the etiology of meningitis can vary, the symptoms are usually similar. In fact, signs and symptoms of meningitis can be similar to those of other diseases such as encephalitis or brain abscesses, and hence, viral meningitis can be misdiagnosed [25]. There are a number of risk factors that are known to increase one's susceptibility to contracting viral meningitis, including compromised immunity, age, travel history, and HIV infection [7]. For more than 100 years, meningitis was assessed by the presence of Brudzinski's sign, Kering's sign, or nuchal rigidity, which are the best-known bedside tests used by physicians to assess whether a patient should have a lumbar puncture. Brudzinski's sign is identified when severe neck stiffness results in knees and hips bending when the neck is flexed [26]. Kering's sign is identified when there is resistance or pain when the patient's knee is flexed to a 90-degree angle and the leg is slowly straightened by the physician [27]. Although these signs are widely used, studies have shown that the diagnostic accuracy of these physical assessments are not significantly different between meningitis cases and normal cases [26]. Therefore, it is advised that patients with suspected meningitis undergo a lumber puncture regardless of the presence or absence of these physical signs [27]. Patients with meningitis usually suffer from fever, chills, abdominal pain, nausea, and headache [5]. Other manifestations of the disease include short and fast breathing, loss of appetite, neck stiffness and pain, and sensitivity to bright light [28]. In addition, difficulty in focusing or concentrating as well as double vision can also be associated with meningitis and may continue after recovery [29]. Skin rash is also observed with certain types of meningitis and is considered a late sign of bacterial meningitis, where the pathogen in the blood targets the capillary cells, leading to their damage [30]. Children are usually less likely to present with meningeal complications and usually present with nonspecific illness, which makes meningitis more likely to be misdiagnosed in children [31].

Diagnosis of meningitis starts with a physical examination and a review of the patient's health history for any of the signs mentioned above. A recent and less recognized physical examination technique that has been developed to assess meningeal irritation is known as jolt accentuation of headache. A systematic review done by Iguchi and colleagues showed that jolt accentuation can be used in emergency settings to exclude meningitis. However, the pooled sensitivity and specificity of this test $(65.3 \%, 70.4 \%$ respectively) are considered low, and more research is needed to assess its usefulness [32]. To test for etiological agents, a lumbar puncture and collection of CSF is needed. The procedure is performed while the patient is in a lying or sitting position, and a hollow needle is injected into the subarachnoid space between vertebrae L3, L4 or L5, where the CSF is aspirated [33]. The CSF is then tested to determine red blood cell and leukocyte count as well as the glucose and protein levels. The cell counts typically help in differentiating the different types of meningitis. For instance, a high WBC count $(\geq$ 500 cells $/ \mu \mathrm{l})$ with a large proportion of neutrophils $(>80 \%)$ is usually observed in bacterial meningitis. Furthermore, in bacterial meningitis, the CSF glucose level typically does not exceed $(300 \mathrm{mg} / \mathrm{dL})$, but a decreased glucose $\mathrm{CSF} /$ blood ratio $(<0.4)$, and an elevated protein level $(1 \mathrm{~g} / \mathrm{l})$ are indications of bacterial meningitis [2]. In addition, the concentration of lactic acid ( $\geq 4.2 \mathrm{mmol} / \mathrm{l})$ can be used to differentiate between viral and bacterial meningitis with $100 \%$ specificity [34]. Gram staining and bacterial culture are the key diagnostic tools for identifying bacterial infections [2], and viral meningitis is suspected when Gram staining and culture of CSF are negative. In viral meningitis, the WBC count typically ranges between 80 and 100 cells/ $\mu$ l (pleocytosis), with a large proportion of lymphocytes (>80\%) [21]. Also, glucose and protein levels usually remain normal [35]. Pleocytosis generally is considered an important criterion for diagnosis of viral meningitis. However, a number of studies have shown that pleocytosis is often not observed in EV meningitis cases involving infants $(38 \%)$ or children $(39 \%)$, or when a lumbar puncture is performed at an early stage 
of disease [36, 37]. The reason for this is not known, but it might be explained by the immaturity of the immune system in young children [38]. The presence of neutrophilic pleocytosis is usually indicative of bacterial meningitis rather than viral meningitis. However, it has been found that $25 \%$ of patients with CNS abnormalities caused by viral agents have neutrophilic pleocytosis [39]. Moreover, a study showed that $47 \%$ of study subjects with enteroviral meningitis had neutrophilic pleocytosis [40].

The gold standard tool for diagnosis of viral meningitis is the polymerase chain reaction (PCR), which detects and quantifies viral DNA or RNA in the patient's CSF [41]. A study of EV-positive meningitis cases in pediatric patients showed that testing of CSF samples by real-time PCR (RTPCR) resulted in $100 \%$ sensitivity, compared to only $38 \%$ sensitivity when using viral culture. Similarly, in a study of $\mathrm{HPeV}$-positive meningitis cases, $100 \%$ sensitivity was achieved with RT-PCR, while viral culture failed to detect the virus [42]. A recent case report described a 9-day-old newborn admitted to the emergency department with nonspecific symptoms of fever and irritability. Molecular analysis (RT-PCR and sequencing) showed that the patient was positive for EV (specifically, E-25) and viral meningitis was diagnosed [43]. However, since obtaining CSF is difficult, alternative specimens, such as blood, throat or nasal swabs, or stool samples might be used instead, particularly in cases of suspected EV infections [44]. On the other hand, diagnosis of mumps virus, herpesvirus, arboviruses, and human immunodeficiency virus (HIV) infections can be achieved using serological assays, although the results might be negative at early stages of the disease. Hence, a second sample should be obtained after two weeks and tested again for the presence of viral agents [5]. Next-generation sequencing (NGS) was recently used in a number of studies to detect a wide variety of pathogens, including viruses, the possible application of this technique as a diagnostic tool in meningitis cases is not yet clear, and more studies are required [45].

\section{Pathogenesis}

The pathogenesis of viral meningitis begins when the causative agent enters the host through respiratory secretions or by the fecal-oral route to cause primary infection in the respiratory or gastrointestinal (GI) tract. This is followed by secondary infection of the CNS, causing meningitis or other neurological problems. Viral infection of the CNS can occur through different mechanisms, such as infection of the choroid plexus epithelium, infection of the lymphoid tissue, induction of inflammation and blood-brain barrier (BBB) breakdown, and infection of peripheral sensory neural pathways [46-49] (Fig. 1). Once the viral agent enters the CNS, increased levels of chemoattractants, neutrophils, CD8 T cells, and monocytes are detected, indicating the induction of an immune response [46]. One study using a murine viral meningitis model in which mice were infected with lymphocytic choriomeningitis virus (LCMV) showed elevated levels of both IL-6 and INF- $\gamma$ in CSF [50]. Another study showed an increased level of IL-1 $\beta$ (a pro-inflammatory cytokine) in patients with aseptic meningitis [51]. Therefore, a strong inflammatory immune response is induced during aseptic meningitis and plays an important role in the pathogenesis of the disease. However, the pathogenesis of aseptic meningitis is not well understood, and it is difficult to study due to limited data. Moreover, it is made harder by the fact that most viral meningitis cases go undetected, and fatal cases manifest as severe encephalitic syndrome rather than meningitis
Fig. 1 Schematic presentation of the general features of viral meningitis pathogenesis

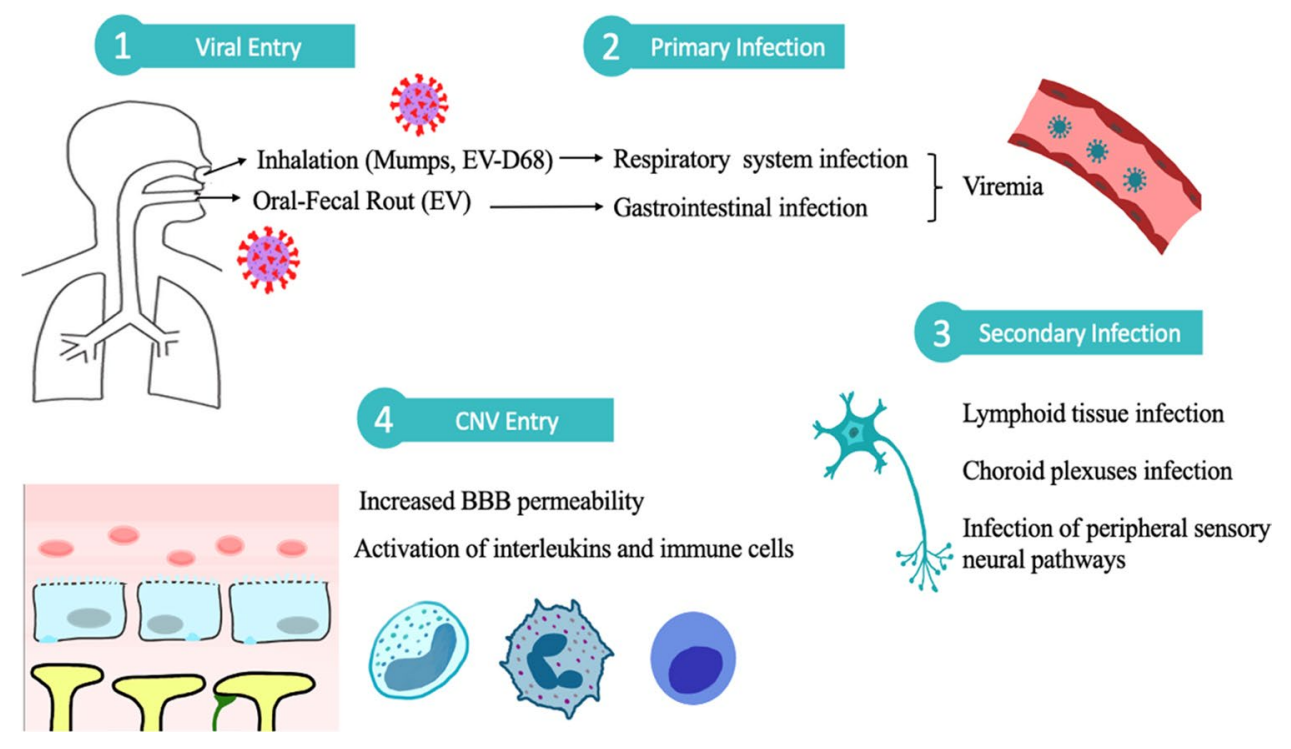


[29]. Research in this area is needed to develop and improve therapeutic interventions against this disease.

\section{Family Picornaviridae}

\section{Enteroviruses (EVs)}

Infection with EVs can lead to different clinical outcomes, such as respiratory illness, hepatitis, pancreatitis, myocarditis, and hand, foot, and mouth (HFM) disease [52, 53]. Enteroviruses can be transmitted through respiratory secretions or by the fecal-oral route [54]. They can also undergo vertical transmission from an infected mother to her infant by crossing the placenta or through breastfeeding [55]. As the virus enters the body, it replicates mainly in the epithelium cells of the nasopharynx and the oropharyngeal and intestinal mucosa [56]. In most cases, the virus enters the body through the oral-fecal route until it reaches the lower gastrointestinal (GI) tract, where it binds to a specific receptor on the surface of enterocytes and crosses the lining of the intestine, reaching the Peyer's patches, where it continues its replication [57]. For a better understanding of the pathogenesis of meningitis, it is important to investigate the interplay between EV-infected cells and the progression of neurological disease, since each cell produces a different response upon infection. Various studies have shown that EVs infect different neural cells, such as glia cells and astrocytes [56]. For example, EV-71 and coxsackievirus B have been detected in undifferentiated neural progenitor cells in mice after infection $[58,59]$. In addition, EV-D68 strains were able to infect and replicate in a human neuroblastoma cell line and a postnatal cortical neuron culture, but non-neurotropic strains were not [60]. Also, the virus could reach the bloodstream by infecting immune cells and cause secondary infections at other sites, such as the heart and CNS [61]. This dissemination of the virus leads to different complications, such as meningitis and encephalitis [62].

Coxsackievirus B, a member of the species Enterovirus $B$, is known to cause meningitis and other neurological disorders [63]. A proposed route of coxsackievirus entry to the CNS is through infected mononuclear cells (Mac-3) that can penetrate the BBB and invade the choroid plexus epithelium, allowing the spread of the virus into the CNS $[64,65]$. This leads to the activation of extracellular signal-regulated kinases 1 and 2 (ERK-1/2), subsequently promoting viral replication inside leukocytes, mainly T cells [66]. Another study demonstrated that this virus replicates in monocytes, $\mathrm{T}$ cells, and $\mathrm{B}$ cells during the viremia phase and that the level of susceptibility of immune cells to infection determines the severity of secondary organ damage [67], such as causing severe meningitis after reaching the CNS. Moreover, analysis of brain tissues obtained from mice born to mothers inoculated with coxsackievirus B4 showed signs of meningitis and accumulation of immune cells (mainly $\mathrm{T}$ cells) and increased secretion of inflammatory cytokines and chemokines (IL6, TNF- $\alpha$, IFN $\alpha$ and MCP-1) [68]. Echoviruses, such as E-6, E-9, E-11, E-13, E-19, and E-30 also belong to the species Enterovirus $B$ and are commonly known to be associated with viral meningitis in children [69]. Different studies have shown that echoviruses use a special type of integrin ( $\alpha 2 \beta 1$, very late antigen 2 [VLA$2])$ and decay-accelerating factor as receptors to infect host cells to cause meningitis and febrile illness [70]. In a study by Lee et al. on aseptic meningitis, it was found that E-30 affects the triple functional domain (TRIO) protein, leading to neural damage (Fig. 2) [71]. E-30 can cause neural damage by modulating the function of the TRIO protein. In the first pathway, the virus affects the function of guanine exchange factor domain 2 (GEFD2), which results in the activation of Ras homology family member A (RhoA), a GTPase signaling protein. This activates both the ROCK and MLC signaling pathways. This cascade of events leads to actin formation and elevation of the nitric oxide level, resulting in CNS complications [71].

Enterovirus D68 (EV-D68) is the most common member of the species Enterovirus $D$ found to be associated with the development of aseptic meningitis. EV-D68 can cause CNS complications in children, commonly meningitis and flaccid paralysis [72]. The pathogenesis of EV-D68 is quite different from that of other enteroviruses, since it is a respiratory virus. As the virus enters the upper respiratory tract (URT), it binds to the $N$-acetylneuraminic acid $\alpha 2$,6-galactose receptor found on the surface of the epithelial cells. This receptor is predominant in the upper respiratory tract (URT) [73], which could explain the limited spread of the virus and its rare progression to neurological complications, such as meningitis. It has also been found that the virus binds to the cellular receptor ICAM-5/telencephalin, which is expressed in dendrites and some neurons, to enter the cell $[74,75]$. In addition, EV-D68 can reach the CNS through binding to the functional receptors of the olfactory nerve in the nasal cavity [76]. The neuropathogenesis of EV-D68 and its ability to infect neuron cells may highlight the potential link between EV-D68 infection and aseptic meningitis.

\section{Human parechovirus (HPeV)}

$\mathrm{HPeV}$ can be transmitted from person to person through respiratory secretions and saliva, leading primarily to respiratory infections [77]. However, it can also cause neurological diseases, such as meningitis and encephalitis, particularly in children [78]. HPeV-3 is the HPeV type that is most commonly associated with viral meningitis [79]. Moreover, it has been found that HPeV-3 utilizes an RBS-receptor binding site other than the arginine-glycine-glutamic acid sequence motif at the carboxyl terminus of VP (capsid protein) that 
Fig. 2 Echovirus 30 affects the TRIO protein, leading to neural damage and CNS complications.

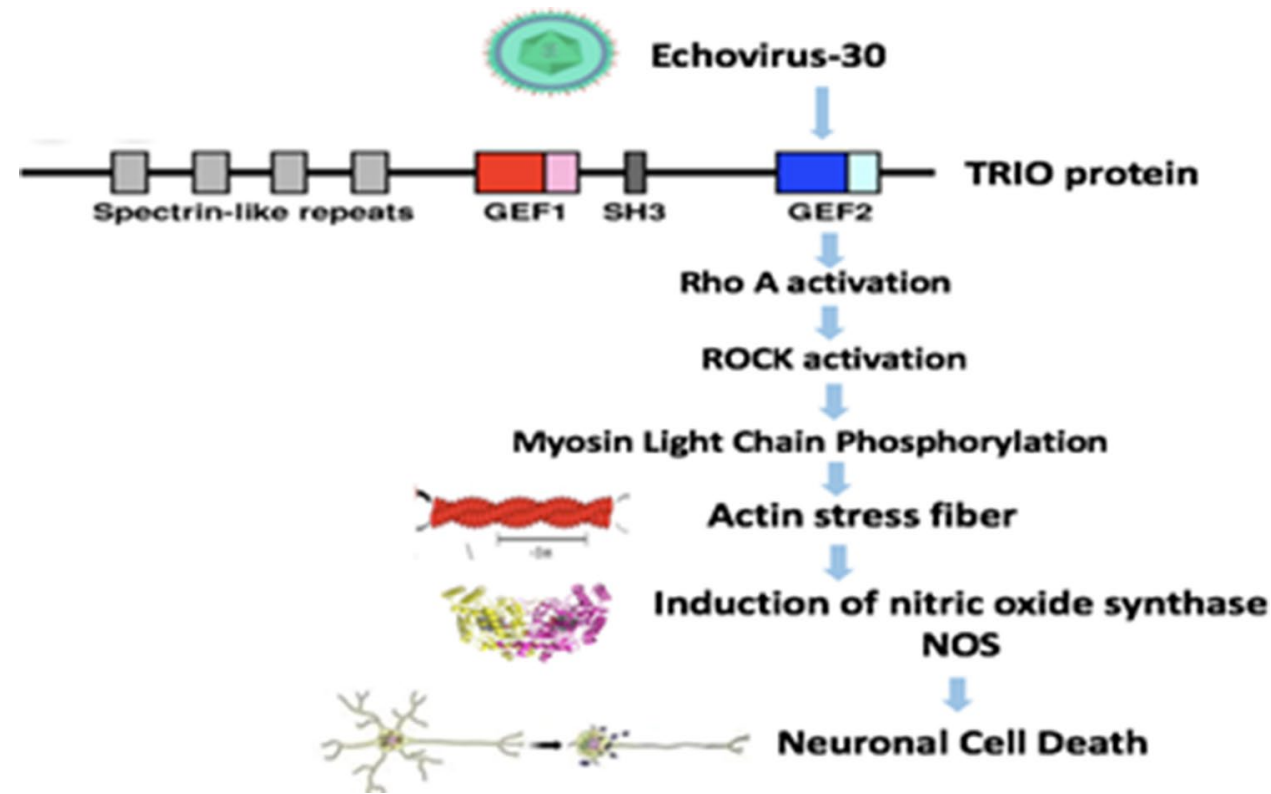

is utilized by the other serotypes of $\mathrm{HPeV}$ [80]. To date, no receptor has been identified for HPeV-3 [81] that would explain its different tropism. In fact, the lack of a receptor in the respiratory tract might explain why HPeV-3 commonly causes meningitis and neonatal sepsis, while HPeV-1 causes respiratory and gastrointestinal illness.

\section{Family Herpesviridae}

Major members of the family Herpesviridae that can cause meningitis include human herpesvirus 1 and 2 (HSV-1 and HSV-2), varicella-zoster virus (VZV), and Epstein-Barr virus (EBV) [82]. The major neurological consequences of HSV are encephalitis and meningitis [83, 84]. All of these viruses are known to cause meningitis and can establish a latent infection in neurons, which can be reactivated [82]. Four glycoproteins in HSV-1 and HSV-2 are important for viral entry ( $\mathrm{gB}, \mathrm{gD}, \mathrm{gH}$, and $\mathrm{gL})$; however, cell binding is mediated by only two glycoproteins, $\mathrm{gB}$ and/or $\mathrm{gC}$, that bind to cell-surface heparan sulfate [82]. Three known cellular receptors have been identified for HSV: 1) herpesvirus entry mediator (HVEM), 2) members of the immunoglobulin superfamily, and 3) heparan sulfate generated by certain isoforms of 3-O-sulfotransferases [82]. HVEM is present on the surface of various cell types, including epithelial cells and neurons. Accordingly, viral entry through this receptor is suggested in meningitis. EBV pathogenesis starts when the virus infects oropharyngeal epithelium cells. It then spreads to the lymphoid tissue and infects lymphoid cells, mainly B cells. In the infected B cell population, the virus can be latent or, less frequently, lytic. In the latent stage, the virus mainly expresses EBNAs (Epstein-Barr nuclear antigens) and LMPs (latent membrane proteins) [85]. The virus can also infect the endothelial cells of blood vessels in the brain, causing latent infection. When the brain undergoes stress, the virus can be activated and the expression of different cytokines and chemokines, such as IL-1, TNF- $\alpha$, IL-12 and IL18 increases, resulting in an inflammatory response [86].

\section{Family Orthomyxoviridae}

Human influenza viruses often cause pneumonia and acute respiratory distress syndrome (ARDS) [87], but on rare occasions, they can cause extra-respiratory illnesses, including meningitis [87], encephalitis [88], meningoencephalitis, and myelitis [89]. Studies have shown that the influenza virus enters the CNS by the olfactory route [90] and other cranial nerves [91]. Typically, the virus binds to $\alpha 2,6$-linked sialic acid and $\alpha 2,3$-linked sialic acid found on epithelial cells of the upper and lower respiratory tract [92]. However, a study showed that $\alpha 2,6$-linked sialic acid and $\alpha 2,3$-linked sialic acid receptors are also found in neurons of the cerebral cortex and brainstem [91, 93]. Collectively, this can explain the spread of influenza virus to the CNS, where it has the potential to cause various neurological syndromes, such as meningitis. 


\section{Arboviruses}

Several arboviruses of different families have been associated with CNS infection and development of meningitis. These include members of the families Flaviviridae (e.g., West Nile virus [WNV]), Togaviridae (e.g., Eastern equine encephalitis virus), and Peribunyaviridae (e.g., La Crosse virus). Most of these viruses are zoonotic and are transmitted to humans through arthropods such as mosquitoes, ticks, and sandflies. The most important arbovirus associated with CNS complications is WNV [94]. In the case of the arboviruses, viral entry can occur through skin bites from infected arthropods, which results in regional lymph node infection, viremia, and spread to the CNS, leading to meningitis [29].

West Nile virus commonly causes West Nile neuroinvasive disorders (WNNDs), such as aseptic meningitis, paralysis, and encephalitis. The pathogenesis of the virus depends mainly on the replication of virus in the host's lymph nodes and skin keratinocytes [95], resulting in primary viremia. The virus can then spread to secondary locations such as CNS after penetrating the BBB [96]. Infection of the CNS by WNV activates Toll-like receptor 3, increases the concentration of TNF- $\alpha$ and other pro-inflammatory factors, which in turn increases the permeability of the BBB and leads to neural death [96]. Therefore, WNV infection can trigger the development of various neurological complications, including meningitis.

\section{Management}

Although patients with viral meningitis usually do not need to be hospitalized, treatment should be provided, such as antipyretics, antiemetics, and analgesics, which can be taken at home. However, some patients, such as those who suffer from seizures, need to be under medical supervision [5]. Although corticosteroids are commonly given in cases of suspected bacterial meningitis to reduce the inflammatory effect that accompanies the disease, there is a lack of evidence of their efficacy against viral meningitis, and more studies are still needed [97]. Pleconaril is an antiviral drug that acts as an inhibitor of enterovirus replication by targeting the viral capsid structure [98]. It is licensed as intranasal therapy for the common cold, but it attains several-fold higher concentrations in the CNS, making it a potential treatment for brain-related diseases such as meningitis [99]. Several studies have shown that pleconaril plays an important role in shortening the course of symptoms, especially headache $[6,99]$. However, other studies have shown that there was no significant difference between treatment and placebo groups [100]. The FDA did not approve the oral usage of the drug because it induces CYP3A enzyme activity, resulting in a drug interaction, especially with oral contraceptives
[101]. In a study done in the UK, researchers found that the median length of hospital stay was 4 days for patients with viral meningitis and nine days for those under antiviral therapy. They also concluded that delays in performing lumbar puncture and unnecessary treatments were associated with prolonged hospital stays and long-term morbidity [8]. No specific treatment is prescribed for aseptic meningitis cases, and supportive medications are usually given to minimize disease complications such as fever and headache, and full recovery takes from 5 to 14 days in the majority of cases [5]. Regarding to HSV treatment, one study showed that antiviral therapy in immunocompromised patients with HSV-induced meningitis should be started immediately and that any delay in the administration of treatment can result in the development of adverse complications [102]. The use of acyclovir against HSV-2-induced meningitis was also evaluated, with better outcomes observed in treated patients. However, one patient developed concentration difficulties as a meningitis symptom that lasted for approximately three months [103]. Recently, a promising drug called psoromic acid (a bioactive lichen-derived compound) has been found to inhibit the replication of both HSV-1 and HSV-2 by inhibiting proteases and DNA polymerases, which makes it a possible drug for treating meningitis caused by HSV [104]. Valacyclovir was also tested in clinical trials for its antiviral suppression ability on recurrence of meningitis. However, treatment with valacyclovir (twice daily) did not prevent recurrent meningitis and was not recommended for this purpose $[105,106]$. Some vaccines have been developed for some viruses such as EV-71 [107], considering its clinical significance, and the different types of EV-71 vaccines are summarized in Table 4.

Recently, an EV-D68 virus-like particle vaccine (VLP) has been developed [108]. The VLP is composed of a recombinant baculovirus expressing $3 \mathrm{CD}$ protease and $\mathrm{P} 1$ precursor. Clinical trials showed a high efficacy of the vaccine [108]. Moreover, V-7404 (viral polymerase inhibitor) and DAS181 (sialidase) are newly developed drugs against EV-D68 $[73,76]$. A recent systematic analysis showed that most viral meningitis cases have a good long-term clinical outcome and that patients with viral meningitis have a better outcome after hospital discharge than patients with viral encephalitis [109].

\section{Conclusion}

Viral meningitis is considered one of the most common clinical conditions affecting different age groups. It often goes undetected or leads to a self-limited disease in adults. However, severe complications can develop in infants and children, including high fever, mental retardation, and even death in some cases. Many viral causative agents are found 
Table 4 The most common types of vaccines developed against EV-71

\begin{tabular}{lll}
\hline Type of vaccine & Composition & Advantages \\
\hline Virus-like particle (VLP) & $\begin{array}{l}\text { SP70 epitope (EV-71) + CVA16 structural protein } \\
\text { or } \\
\text { SP70 epitope (EV-71) + hepatitis B core antigen } \\
\text { Adenovirus (E1/E3 deleted) + EV71 P1 and 3CD genes }\end{array}$ & $\begin{array}{l}\text { Highly immunogenic with the production of neutralizing } \\
\text { antibodies at high titers }\end{array}$ \\
$\begin{array}{ll}\text { Recombinant vaccine } \\
\text { Live attenuated vaccine }\end{array}$ & $\begin{array}{l}\text { Experiments were done using EV71(S1-3') from geno- } \\
\text { type A }\end{array}$ & $\begin{array}{c}\text { Reduces the viral load by activating IFN- } \gamma, \text { IL-17, IL-4, } \\
\text { and IL-13 } \\
\text { C4 } 4\end{array}$ \\
\hline
\end{tabular}

to be associated with aseptic meningitis, such as enterovirus, parechovirus, and herpesviruses. Therefore, knowing the most common causative agents responsible for aseptic meningitis will help in better understanding the disease, and hence provide the basis for the development of preventative and control programs. Molecular epidemiology studies of viral meningitis are scarce in many countries, including the MENA region. Accordingly, more studies should be conducted to understand the etiology and pathogeneses of this illness to develop new therapeutic interventions that will help in improving outcome.

Author contributions HMY developed the concept. AK and SJ wrote the initial draft. MKS revised the first draft and supervised students. All authors read and approved the last version.

Funding This work was supported by funding from Qatar University, Grant Nos. QUHI-BRC-20/21-1 and QUST-2-BRC-2018-1.

\section{Compliance with ethical standards}

Conflict of interest Authors declare no conflict of interest.

\section{References}

1. Logan SA, MacMahon E (2008a) Viral meningitis. BMJ 336(7634):36-40

2. Hoffman O, Weber JR (2009) Pathophysiology and treatment of bacterial meningitis. Ther Adv Neurol Disord 2(6):401-412

3. Booss J, Tselis AC (2014) Chapter 1-a history of viral infections of the central nervous system: foundations, milestones, and patterns. In: Tselis AC, Booss J (eds) Handbook of clinical neurology, vol 123. Elsevier, pp 3-44. https://doi.org/10.1016/ B978-0-444-53488-0.00001-8

4. Hersi K, Gonzalez FJ, Kondamudi NP. Meningitis. [Updated 2020 Nov 21]. In: StatPearls [Internet]. Treasure Island (FL): StatPearls Publishing; 2020 Jan-. Available from: https://www. ncbi.nlm.nih.gov/books/NBK459360

5. Kumar R (2005) Aseptic meningitis: diagnosis and management. Indian J Pediatr 72(1):57-63

6. Desmond R et al (2006) Enteroviral meningitis: natural history and outcome of pleconaril therapy. Antimicrob Agents Chemother 50(7):2409-2414
7. Logan SAE, MacMahon E (2008b) Viral meningitis. BMJ (Clinical research ed.) 336(7634):36-40

8. McGill $\mathrm{F}$ et al (2018) Incidence, aetiology, and sequelae of viral meningitis in UK adults: a multicentre prospective observational cohort study. Lancet Infect Dis 18(9):992-1003

9. Kadambari S et al (2019) Enterovirus and parechovirus meningitis in infants younger than 90 days old in the UK and Republic of Ireland: a British Paediatric Surveillance Unit study. Arch Dis Child 104(6):552-557

10. Hviid A, Melbye M (2007) The epidemiology of viral meningitis hospitalization in childhood. Epidemiology 18(6):695-701

11. Hu Y, Jiang L, Peng H-L (2015) Clinical analysis of 134 children with nervous system damage caused by enterovirus 71 infection. Pediatr Infect Dis J 34(7):718-723

12. Smuts $\mathrm{H}$ et al (2018) Molecular characterization of an outbreak of enterovirus-associated meningitis in Mossel Bay, South Africa, December 2015-January 2016. BMC Infect Dis 18(1):709-709

13. Ortner B et al (2009) Epidemiology of enterovirus types causing neurological disease in Austria 1999-2007: detection of clusters of echovirus 30 and enterovirus 71 and analysis of prevalent genotypes. J Med Virol 81(2):317-324

14. Moriguchi T et al (2020) A first case of meningitis/encephalitis associated with SARS-Coronavirus-2. Int J Infect Dis 94:55-58

15. Dash $\mathrm{N}$ et al (2007) Epidemiology of meningitis in Al-Ain, United Arab Emirates, 2000-2005. Int J Infect Dis 11(4):309-312

16. Dalwai A, Ahmad S, Al-Nakib W (2010) Echoviruses are a major cause of aseptic meningitis in infants and young children in Kuwait. Virol J 7(1):236

17. Abid FB et al (2018) Epidemiology and clinical outcomes of viral central nervous system infections. Int J Infect Dis 73:85-90

18. Abdelkader MM et al (2017) Prevalence of MDR pathogens of bacterial meningitis in Egypt and new synergistic antibiotic combinations. PLoS ONE 12(2):e0171349-e0171349

19. Alzein K (2016) Revision of meningitis surveillance system in Jordan during 2001 and 2014 years. Epidemiol (sunnyvale) 6:220. https://doi.org/10.4172/2161-1165.100022

20. Ghuneim N, Dheir M, AbuAli K (2016) Epidemiology of different types of meningitis cases in gaza governorates, occupied Palestinian Territory, December 2013-January 2014. J Antivir Antiretrovir 8(1):26-34

21. Dumaidi K, Al-Jawabreh A (2017) Molecular detection and genotyping of enteroviruses from CSF samples of patients with suspected sepsis-like illness and/or aseptic meningitis from 2012 to 2015 in West Bank, Palestine. PLoS ONE 12(2):e0172357-e0172357

22. Haydar SM et al (2019) Adherence to international guidelines for the treatment of meningitis infections in Lebanon. Saudi Med J 40(3):260-265

23. Selim HS et al (2007) Microbial study of meningitis and encephalitis cases. J Egypt Public Health Assoc 82(1-2):1-19 
24. Shaker OG, Abdelhamid N (2015) Detection of enteroviruses in pediatric patients with aseptic meningitis. Clin Neurol Neurosurg 129:67-71

25. Visintin C et al (2010) Management of bacterial meningitis and meningococcal septicaemia in children and young people: summary of NICE guidance. BMJ 340:c3209

26. Mehndiratta M et al (2012) Appraisal of Kernig's and Brudzinski's sign in meningitis. Ann Indian Acad Neurol 15(4):287

27. Waghdhare $S$ et al (2010) Accuracy of physical signs for detecting meningitis: a hospital-based diagnostic accuracy study. Clin Neurol Neurosurg 112(9):752-757

28. Parikh V, Tucci V, Galwankar S (2012) Infections of the nervous system. Int J Crit Illn Inj Sci 2(2):82

29. Irani DN (2008) Aseptic meningitis and viral myelitis. Neurol Clin 26(3):635

30. Tsai J, Nagel MA, Gilden D (2013) Skin rash in meningitis and meningoencephalitis. Neurology 80(19):1808-1811

31. Shukla B et al (2017) Aseptic meningitis in adults and children: diagnostic and management challenges. J Clin Virol 94:110-114

32. Iguchi $\mathrm{M}$ et al (2020) Diagnostic test accuracy of jolt accentuation for headache in acute meningitis in the emergency setting. Cochrane Database Syst Rev. https://doi.org/10.1002/14651858. CD012824

33. Walker HK, Hall WD, Hurst JW (eds) (1990) Clinical methods: the history, physical, and laboratory examinations. 3rd edn. Butterworths, Boston.PMID: 21250045

34. Buch K et al (2018) Cerebrospinal fluid lactate as a marker to differentiate between community-acquired acute bacterial meningitis and aseptic meningitis/encephalitis in adults: a Danish prospective observational cohort study. Infect Dis (Lond) 50(7):514-521

35. Seehusen DA, Reeves M, Fomin D (2003) Cerebrospinal fluid analysis. Am Fam Physician 68(6):1103-1108

36. de Crom SC et al (2012) Characteristics of pediatric patients with enterovirus meningitis and no cerebral fluid pleocytosis. Eur $\mathbf{J}$ Pediatr 171(5):795-800

37. Alhazmi A et al (2019) Paediatric enterovirus meningitis without cerebrospinal fluid pleocytosis. J Infect 79(6):612-625

38. Seiden JA et al (2010) Lack of cerebrospinal fluid pleocytosis in young infants with enterovirus infections of the central nervous system. Pediatr Emerg Care 26(2):77-81

39. Jaijakul $\mathrm{S}$ et al (2017) The clinical significance of neutrophilic pleocytosis in cerebrospinal fluid in patients with viral central nervous system infections. Int J Infect Dis 59:77-81

40. Méchaï $\mathrm{F}$ et al (2010) Caractéristiques clinicobiologiques des méningites à Enterovirus de l'adulte : étude de 59 cas. La Revue de Médecine Interne 31(9):596-599

41. Verstrepen WA et al (2001) Rapid detection of enterovirus RNA in cerebrospinal fluid specimens with a novel single-tube real-time reverse transcription-PCR assay. J Clin Microbiol 39(11):4093-4096

42. De Crom $S$ et al (2013) Prospective comparison of the detection rates of human enterovirus and parechovirus RT-qPCR and viral culture in different pediatric specimens. J Clin Virol 58(2):449-454

43. Alhazmi A et al (2020) Repeated viral meningitis in a newborn. J NeuroVirol 1-3

44. Kupila L et al (2005) Diagnosis of enteroviral meningitis by use of polymerase chain reaction of cerebrospinal fluid, stool, and serum specimens. Clin Infect Dis 40(7):982-987

45. Poplin V, Boulware DR, Bahr NC (2020) Methods for rapid diagnosis of meningitis etiology in adults. Biomark Med 14(6):459479. https://doi.org/10.2217/bmm-2019-0333
46. Kim JV et al (2009) Myelomonocytic cell recruitment causes fatal CNS vascular injury during acute viral meningitis. Nature 457(7226):191-195

47. Wolinsky JS, Klassen T, Baringer JR (1976) Persistence of neuroadapted mumps virus in brains of newborn hamsters after intraperitoneal inoculation. J Infect Dis 133(3):260-267

48. Wong KT et al (2008) The distribution of inflammation and virus in human enterovirus 71 encephalomyelitis suggests possible viral spread by neural pathways. J Neuropathol Exp Neurol 67(2):162-169

49. Munster VJ et al (2012) Rapid Nipah virus entry into the central nervous system of hamsters via the olfactory route. Sci Rep 2(1):736

50. Frei K et al (1988) Production of B cell stimulatory factor-2 and interferon gamma in the central nervous system during viral meningitis and encephalitis. Evaluation in a murine model infection and in patients. J Exp Med 168(1):449-453

51. Ramilo O et al (1990) Detection of interleukin $1 \beta$ but not tumor necrosis factor- $\alpha$ in cerebrospinal fluid of children with aseptic meningitis. Am J Dis Child 144(3):349-352

52. Wells AI, Coyne CB (2019) Enteroviruses: a gut-wrenching game of entry, detection, and evasion. Viruses 11(5):460

53. Akuzawa $\mathrm{N}$ et al (2014) Myocarditis, hepatitis, and pancreatitis in a patient with coxsackievirus A4 infection: a case report. Virol J 11:3-3

54. Burrell CJ, Howard CR, Murphy FA (2017) Chapter 32-picornaviruses. In: Burrell CJ, Howard CR, Murphy FA (eds) Fenner and White's Medical virology (Fifth Edition). Academic, London, pp 447-463

55. Mereaux $J$ et al (2017) Enterovirus infection during pregnancy: Underestimated cause of fetal and neonatal complications? Gynecologie, obstetrique, fertilite \& senologie 45(4):231-237

56. Majer A, McGreevy A, Booth TF (2020) Molecular pathogenicity of enteroviruses causing neurological disease. Front Microbiol 11:540

57. Rotbart HA (2000) Viral meningitis. In: Seminars in neurology. Copyright $\odot 2000$ by Thieme Medical Publishers, Inc

58. Huang H-I et al (2014) Enterovirus 71 infects brain-derived neural progenitor cells. Virology 468-470:592-600

59. Puccini JM et al (2014) Distinct neural stem cell tropism, early immune activation, and choroid plexus pathology following coxsackievirus infection in the neonatal central nervous system. Lab Invest 94(2): 161-181

60. Brown DM et al (2018) Contemporary circulating enterovirus D68 strains have acquired the capacity for viral entry and replication in human neuronal cells. mBio 9(5):e01954-e2018

61. Palacios G, Oberste M (2005) Enteroviruses as agents of emerging infectious diseases. J Neurovirol 11(5):424-433

62. de Crom SCM et al (2016) Enterovirus and parechovirus infection in children: a brief overview. Eur J Pediatr 175(8):1023-1029

63. Berger JR et al (2006) Persistent coxsackie B encephalitis: report of a case and review of the literature. J NeuroVirol 12(6):511-516

64. Tabor-Godwin JM et al (2010) A novel population of myeloid cells responding to coxsackievirus infection assists in the dissemination of virus within the neonatal CNS. J Neurosci 30(25):8676-8691

65. Huang H-I, Shih S-R (2015) Neurotropic enterovirus infections in the central nervous system. Viruses 7(11):6051-6066

66. Opavsky MA et al (2002) Enhanced ERK-1/2 activation in mice susceptible to coxsackievirus-induced myocarditis. J Clin Investig 109(12):1561-1569

67. Hwang JY et al (2012) Characterization of infections of human leukocytes by non-polio enteroviruses. Intervirology 55(5):333-341 
68. Jmii $\mathrm{H}$ et al (2020) Immunopathology in the brain of mice following vertical transmission of Coxsackievirus B4. Microb Pathog 103965

69. Kim H-J et al (2012) Epidemics of viral meningitis caused by echovirus 6 and 30 in Korea in 2008. Virol J 9:38-38. https://doi. org/10.1186/1743-422X-9-38

70. Stewart PL, Dermody TS, Nemerow GR (2003) Structural basis of nonenveloped virus cell entry. Adv Protein Chem 64:455-491

71. Lee J-W et al (2012) Echovirus 30 induced neuronal cell death through TRIO-RhoA signaling activation. PLoS ONE 7(5):e36656-e36656

72. González-Sanz R et al (2019) Enterovirus D68-associated respiratory and neurological illness in Spain, 2014-2018. Emerg Microbes Infect 8(1):1438-1444

73. Esposito S et al (2015) Enterovirus D68 infection. Viruses 7(11):6043-6050

74. Sun J, Hu X-Y, Yu X-F (2019) Current understanding of human enterovirus D68. Viruses 11(6):490

75. Wei $\mathrm{W}$ et al (2016) ICAM-5/telencephalin is a functional entry receptor for enterovirus D68. Cell Host Microbe 20(5):631-641

76. Messacar K et al (2018) Enterovirus D68 and acute flaccid myelitis-evaluating the evidence for causality. Lancet Infect Dis 18(8):e239-e247

77. Romero JR, Modlin JF (2015) 175-human parechoviruses. In: Bennett JE, Dolin R, Blaser MJ (eds) Mandell, Douglas, and Bennett's principles and practice of infectious diseases (Eighth Edition). Content Repository Only!: Philadelphia, pp 2091-2094. e2.

78. Johannessen I, Burns SM (2012) 48-picornaviruses: meningitis; paralysis; rashes; intercostal myositis; myocarditis; infectious hepatitis; common cold. In: Greenwood D et al (eds) Medical microbiology (Eighteenth Edition). Churchill Livingstone, Edinburgh, pp 483-496

79. Wolthers $\mathrm{KC}$ et al (2008) Human parechoviruses as an important viral cause of sepsislike illness and meningitis in young children. Clin Infect Dis 47(3):358-363

80. Westerhuis B (2014) The 3-dimensional play of human parechovirus infection; cell, virus and antibody

81. Karelehto $\mathrm{E}$ et al (2018) Polarized entry of human parechoviruses in the airway epithelium. Front Cell Infect Microbiol 8:294-294. https://doi.org/10.3389/fcimb.2018.00294

82. Spear PG, Longnecker R (2003) Herpesvirus entry: an update. J Virol 77(19):10179-10185

83. Bergström T et al (1990) Primary and recurrent herpes simplex virus type 2-induced meningitis. J Infect Dis 162(2):322-330

84. Whitley RJ, Lakeman F (1995) Herpes simplex virus infections of the central nervous system: therapeutic and diagnostic considerations. Clin Infect Dis 20(2):414-420

85. Akkoc $\mathrm{G}$ et al (2016) Epstein-Barr virus encephalitis in an immunocompetent child: a case report and management of EpsteinBarr virus encephalitis. Case Rep Infect Dis 2016

86. Koyuncu OO, Hogue IB, Enquist LW (2013) Virus infections in the nervous system. Cell Host Microbe 13(4):379-393. https:// doi.org/10.1016/j.chom.2013.03.010

87. Liang C-Y, Yang C-H, Lin J-N (2018) Focal encephalitis, meningitis, and acute respiratory distress syndrome associated with influenza A infection. Med Princ Pract 27(2):193-196

88. Sejvar JJ, Uyeki TM (2010) Neurologic complications of 2009 influenza A (H1N1). Neurology 74(13):1020

89. Xia J-B et al (2014) H7N9 influenza A-induced pneumonia associated with acute myelitis in an adult. Intern Med 53(10):1093-1095

90. Yamada M et al (2012) Multiple routes of invasion of wild-type Clade 1 highly pathogenic avian influenza $\mathrm{H} 5 \mathrm{~N} 1$ virus into the central nervous system (CNS) after intranasal exposure in ferrets. Acta Neuropathol 124(4):505-516
91. Siegers JY et al (2019) Viral factors important for efficient replication of influenza A viruses in cells of the central nervous system. J Virol 93(11):e02273-e2318

92. Imai M, Kawaoka Y (2012) The role of receptor binding specificity in interspecies transmission of influenza viruses. Curr Opin Virol 2(2):160-167

93. Kim M et al (2013) Comparative analyses of influenza virus receptor distribution in the human and mouse brains. J Chem Neuroanat 52:49-57

94. Miller BR (2008) Arboviruses. In: Mahy BWJ, Van Regenmortel MHV (eds) Encyclopedia of virology (Third Edition). Academic Press, Oxford, pp 170-176

95. Lim P-Y et al (2011a) Keratinocytes are cell targets of West Nile virus in vivo. J Virol 85(10):5197-5201

96. Lim SM et al (2011b) West Nile virus: immunity and pathogenesis. Viruses 3(6):811-828

97. Bookstaver PB et al (2017) Management of viral central nervous system infections: a primer for clinicians. J Cent Nerv Syst Dis 9:1179573517703342-1179573517703342

98. Pevear DC et al (1999) Activity of pleconaril against enteroviruses. Antimicrob Agents Chemother 43(9):2109

99. Romero JR (2001) Pleconaril: a novel antipicornaviral drug. Expert Opin Investig Drugs 10(2):369-379

100. Abzug MJ et al (2003) Double blind placebo-controlled trial of pleconaril in infants with enterovirus meningitis. Pediatr Infect Dis J 22(4):335-341

101. Paintsil E, Cheng Y-C (2009) Antiviral agents. In: Schaechter M (ed) Encyclopedia of microbiology (Third Edition). Academic Press, Oxford, pp 223-257

102. Momméja-Marin $\mathrm{H}$ et al (2003) Herpes simplex virus type 2 as a cause of severe meningitis in immunocompromised adults. Clin Infect Dis 37(11):1527-1533

103. Bergström T, Alestig K (1990) Treatment of primary and recurrent herpes simplex virus type 2 induced meningitis with acyclovir. Scand J Infect Dis 22(2):239-240

104. Hassan STS et al (2019) Psoromic acid, a lichen-derived molecule, inhibits the replication of HSV-1 and HSV-2, and inactivates HSV-1 DNA polymerase: shedding light on antiherpetic properties. Molecules (Basel, Switzerland) 24(16):2912

105. Aurelius E et al (2012) Long-term valacyclovir suppressive treatment after herpes simplex virus type 2 meningitis: a double-blind, randomized controlled trial. Clin Infect Dis 54(9):1304-1313

106. Kato $\mathrm{K}$ et al (2015) Recurrent neonatal herpes simplex virus infection with central nervous system disease after completion of a 6-month course of suppressive therapy: case report. J Infect Chemother 21(12):879-881

107. Yi E-J et al (2017) Enterovirus 71 infection and vaccines. Clin Exp Vaccine Res 6(1):4-14

108. Dai W et al (2018) A virus-like particle vaccine confers protection against enterovirus D68 lethal challenge in mice. Vaccine 36(5):653-659

109. Hudson JA et al (2020) Outcomes beyond hospital discharge in infants and children with viral meningitis: a systematic review. Rev Med Virol 30(2):e2083

110. Biaukula VL et al (2012) Meningitis in children in Fiji: etiology, epidemiology, and neurological sequelae. Int J Infect Dis 16(4):e289-e295

111. Nigrovic LE et al (2013) Trends in the management of viral meningitis at United States children's hospitals. Pediatrics 131(4):670-676

112. Frantzidou $\mathrm{F}$ et al (2008) Aseptic meningitis and encephalitis because of herpesviruses and enteroviruses in an immunocompetent adult population. Eur J Neurol 15(9):995-997 
113. Han S-H et al (2016) Etiology of aseptic meningitis and clinical characteristics in immune-competent adults. J Med Virol 88(1):175-179

114. Magazzini $\mathrm{S}$ et al (2012) Clinical picture of meningitis in the adult patient and its relationship with age. Intern Emerg Med 7(4):359-364

115. Kupila L et al (2006) Etiology of aseptic meningitis and encephalitis in an adult population. Neurology 66(1):75-80
116. Meqdam MM, Khalousi MM, Al-Shurman A (2002) Enteroviral meningitis in northern Jordan: prevalence and association with clinical findings. J Med Virol 66(2):224-228

Publisher's Note Springer Nature remains neutral with regard to jurisdictional claims in published maps and institutional affiliations. 